\title{
Assessment of activity concentration and effective doses from bioassay sample of occupational workers in NINMAS, Bangladesh
}

\begin{abstract}
This aim of this study is to estimate the activity concentration and committed effective doses from Bioassay sample such as urine samples of Nuclear Medicine workers due to intake of ${ }^{131} \mathrm{I}$ and ${ }^{99 \mathrm{~m}} \mathrm{Tc}$. For internal radiation monitoring, 37 urine samples are collected from occupational workers of National Institute of Nuclear Medicine and Allied Science (NINMAS) in Bangladesh. These urine samples have been analyzed using High Purity Germanium (HPGe) detector. The radioactivity of ${ }^{131} \mathrm{I}$ and ${ }^{99 \mathrm{~m}} \mathrm{Tc}$ were found $5.78 \pm 0.861 \mathrm{BqL}^{-1}$ to $389.95 \pm 30.01 \mathrm{BqL}^{-1}$ and $24.47 \pm 2.14 \mathrm{BqL}^{-1}$ to $1529.5 \pm 36.05 \mathrm{BqL}^{-1}$ respectively. The effective doses of occupational workers have been also calculated using the radioactivity concentration and the dose coefficients which were given in ICRP publication 78. For manipulating the unsealed source of ${ }^{99 m} \mathrm{Tc}$, the highest and lowest effective doses were 48.8 and $1.15 \mu \mathrm{Sv}$ respectively, for handling 560 and $120 \mathrm{mCi}$ of ${ }^{99 \mathrm{~m}} \mathrm{Tc}$ radionuclide. On the other hand, the highest and lowest effective doses were 6.82 and $0.158 \mu \mathrm{Sv}$ respectively, for handling 2000 and $100 \mathrm{mCi}$ of ${ }^{131} \mathrm{I}$ radionuclide. These values are within limits, however to avoid inhalation and contamination of ${ }^{131} \mathrm{I}$ and ${ }^{99 \mathrm{~m}} \mathrm{Tc}$ proper working environment should be established with suitable ventilation system, fume hood, mask, etc.
\end{abstract}

Volume I Issue 2 - 2016

\author{
Jannatul Ferdous,' Sagar Hossain, ${ }^{2}$ Begum F, \\ Md Ashraful Hoque' \\ 'Heath physics Division, Bangladesh \\ ${ }^{2}$ Department of Physics, Dhaka University, Bangladesh \\ ${ }^{3}$ National Institute of Nuclear Medicine and Allied sciences, \\ Bangladesh
}

Correspondence: Jannatul Ferdous, Heath physics Division Atomic Energy Center, Dhaka, Bangladesh, Tel +8801716275050, Email ferdous28@yahoo.com

Received:September 21, 2016 | Published: December 20,

Keywords: radioactivity, effective dose, bioassay sample, occupational worker, nuclear medicine and allied science

\section{Abbreviations: HPGe, high purity germanium; MCA, multi- channel analyzer}

\section{Introduction}

Unsealed radioactive sources such as ${ }^{131} \mathrm{I}$ and ${ }^{99 \mathrm{~m}} \mathrm{Tc}$ are used in Nuclear Medicine Centers, to diagnose and treat patients, pose significant risks of internal exposure to the occupational workers. ${ }^{131}$ I is highly volatile and radiotoxic, which may pose an occupational radiological hazard, especially in places where significant activities are routinely handled. In such situations, worker handling unsealed sources of ${ }^{131}$ I may be internally exposed by inhalation. Though ${ }^{99 \mathrm{~m}} \mathrm{Tc}$ is not as volatile, however it is the most widely used imaging agents in nuclear medicine. Moreover, due to short half life the internal radiation risk that it poses may sometimes be over looked. Although it is recognized that in nuclear medicine centers external exposure is usually higher than internal exposure, the risks associated with intakes should be estimated in each case and, if necessary, staff involved in the handling of unsealed sources should be routinely monitored in order to ensure that individual doses are kept as low as possible. ${ }^{1}$ Internal monitoring should also be performed in response to an accident or suspected inhalation or ingestion intake. ${ }^{131} \mathrm{I}$ is a short-lived radionuclide (half-life; 8days). It decays by beta emission producing photons of $0.36 \mathrm{MeV}$. For adults, it is assumed that, of the iodine reaching the blood, $30 \%$ is transported to the thyroid gland and other $70 \%$ is excreted directly in urine via the urinary bladder. The biological half-life in blood is taken to be $6 \mathrm{~h}$. Iodine incorporated into thyroid hormones leaves the gland with biological half-life of 12days. Most iodine (80\%) is subsequently released and is available in the circulation for uptake by the thyroid or direct urinary excretion; the remainder is excreted via the large intestine in the faeces. Because of the short physical half-life of ${ }^{131} \mathrm{I}$, this recycling is not important in terms of the committed effective dose. Iodine is rapidly absorbed into the circulation following inhalation or ingestion. It is concentrated in the thyroid and excreted predominantly via urine. ${ }^{2}$ There are 17 Nuclear Medicine Centers in Bangladesh, from these Centers only one is selected for this study: National Institute of Nuclear Medicine and Allied Science (NINMAS) Dhaka. While processing and labeling of the liquid sources with labeling compounds, the sources may enter the bodies of the occupational worker through inhalation and ingestion. The present work was taken up to measure the contamination of the occupational staff because of the above radiopharmaceuticals.

\section{Materials and methods}

\section{Collection and preparation of samples}

Workers were advised to read collecting instructions provided together with the pots. The main concern in this methodology was to reduce the possibility of external contamination of the pots. 37 urine samples of 17 occupational workers were collected after 3 to 4 hours of handling of ${ }^{131} \mathrm{I}$ and ${ }^{99 \mathrm{~m}} \mathrm{Tc}$ from the National Institute of Nuclear Medicine and Allied Science (NINMAS), Dhaka. These samples were kept in standard plastic pots previously identified with name, date and time of collection and activity of handling isotope. Samples were processed immediately after collection and measured with the HPGe detector system coupled to a Multichannel Analyzer (MCA) at the Health Physics Division, Atomic Energy Centre, and Dhaka under the Bangladesh Atomic Energy Commission. The volumes of the urine samples were measured and were found to be less than $350 \mathrm{ml}$. Finally, the samples were taken in plastic bags and positioned in the HPGe detector to perform the measurement. Due to several reasons such as 
non availability of radioactive sources, working conditions, etc., it was not possible to collect urine sample periodically.

\section{Radioactivity measurement}

After completion of necessary quality assurance of the HPGe detector the radioactivity of the samples were measured. The liquid nitrogen dewar of the HPGe detector was filled with liquid nitrogen at least 12 hours before the measurement. This allowed sufficient time for cooling of the detector. The detector system was turned on and a 15 minute warm-up period was allowed before the first measurement of each day. The high voltage bias supply to the detector was gradually raised to the operating voltage $(+1600$ Volt.), the amplifier coarse gain, fine gain and peak shaping time were also adjusted to the desired values. ${ }^{3}$ After all these settings had been done, a period of about half an hour was allowed for stabilization of the system. Then the energy calibration of the detector was checked by placing ${ }^{137} \mathrm{Cs}$ and ${ }^{60} \mathrm{Co}$ point sources at the detector axis with a source-to-detector distance at about $10 \mathrm{~cm}$ for 100 seconds, so that $661.66 \mathrm{keV}, 1170 \mathrm{keV}$, and $1332 \mathrm{keV}$ peaks could appear in the appropriate channels. Then a background spectrum was obtained by placing an empty plastic container on the top of the well-shielded detector head for 5000seconds. After taking the background reading, each of the sample-filled plastic containers was placed on top of the detector head and then the entrance door to the shielding arrangement was closed. The sample's counts were acquired for 5000 seconds. The computer software "Mestro-32" was used to transform the data of each sample. The analysis sheet contained the energy of emitted gamma photons and the corresponding counts per second including the statistical error. After searching for the particular radionuclide's peak and taking the corresponding counts per sec, the total activity for the particular sample was calculated by the following equation,

$$
A=N e t c p s / p_{\gamma} \cdot e . w
$$

Where $\mathrm{A}=$ activity of the radionuclide present in the samples in units of $\mathrm{Bq} \mathrm{l}^{-1}$, cps $=$ counts per sec, $\mathrm{p} \gamma=$ the fraction of a particular gamma-ray energy, $\mathrm{e}=$ efficiency of the detector for a particular gamma-ray energy (emitted from the specific radionuclide of interest), $\mathrm{w}=$ Quantity (volume) of the sample in liters.

The mean background reading from a set of measurements was subtracted from each of the sample reading. Every time before carrying an experiment, a number of operations of HPGe detector had to be done, such as

a. Energy calibration,

b. Energy resolution,

c. Efficiency calibration and

d. Estimation of lower limit of detection for each of the detecting radionuclides. During the read out period, the Dewar flask was filled by liquid nitrogen.

\section{Evaluation of committed effective dose}

The concentration of ${ }^{131} \mathrm{I}$ and ${ }^{99 \mathrm{~m}} \mathrm{Tc}$ radionuclides in the urine samples of the nuclear medicine staff, which were measured with HPGe semiconductor detector, were converted into the concentration per daily urinary volume from which the daily intake and the committed effective dose were evaluated using the following equation. ${ }^{4}$

$$
H_{A}=\sum I_{A j} h_{A j}
$$

Where $\mathrm{H}_{\mathrm{A}}$ is the committed effective dose or the committed equivalent dose (Sv) by inhalation for adult, $h_{A j}$ is the inhalation dose coefficient $(\mathrm{Sv} / \mathrm{Bq})$ for the effective dose or for the target organ considered for the radionuclide $j .{ }^{5}$

For an acute intake at time $t$ before the measurement, the activity of the radionuclide inhaled can be calculated by

$$
I_{A j}=E_{j} / e_{a A j}(t)
$$

Where $\mathrm{I}_{A j}$ is the activity (in $\mathrm{Bq}$ ) of the radionuclide $j$ inhaled by a member of adult; $\mathrm{E}_{\mathrm{j}}$ is the whole body activity of the radionuclide $j$ or the activity of the radionuclide $j$ in the organ considered, obtained by direct measurement (in $\mathrm{Bq}) ; \mathrm{e}_{\mathrm{aAj}}(\mathrm{t})$ is the fractional activity in total body or in the organ considered at time $t$ after an acute inhalation ' $a$ ' of the radionuclide $j$ by a member of age group adult. Values of $\mathrm{e}_{\mathrm{aAj}}(\mathrm{t})$ have been calculated using the biokinetic models and data described in ICRP Publication 78.

\section{Results and discussion}

\section{Activity concentration of ${ }^{131} \mid \mathrm{\&}{ }^{99 \mathrm{~m}} \mathrm{TC}$}

As it is seen in the Table $1 \& 2$, the concentration of ${ }^{131}$ I radionuclide was observed in 14 samples, whereas presence of ${ }^{99 \mathrm{~m}} \mathrm{Tc}$ was detected in 14 samples. No radioactivity was observed in the rest of the 9 samples because in those samples the radioactivity concentration is in minimum detection level.

The concentration ranges of ${ }^{131} \mathrm{I}$ was from $5.78 \pm 0.861 \mathrm{BqL}^{-1}$ to $389.95 \pm 11 \mathrm{BqL}^{-1}$ and the concentration ranges of ${ }^{99 \mathrm{~m}} \mathrm{Tc}$ was from $24.47 \pm 2.14 \mathrm{BqL}^{-1}$ to $1529.5 \pm 36.05 \mathrm{BqL}^{-1}$. The highest and lowest detected radioactivity concentrations of ${ }^{131} \mathrm{I}$ in urine samples were $389.95 \pm 11 \mathrm{BqL}^{-1}$ and $5.78 \pm 0.861 \mathrm{BqL}^{-1}$ respectively, whereas the highest and the lowest detected radioactivity concentrations of ${ }^{99 \mathrm{~m}} \mathrm{Tc}$ in urine samples were $1529.5 \pm 36.05 \mathrm{BqL}^{-1}$ and $24.47 \pm 2.14 \mathrm{BqL}^{-1}$ respectively. There was no radioactivity concentration of ${ }^{99 \mathrm{~m}} \mathrm{Tc}$ in the urine samples of female workers but the concentrations of ${ }^{131}$ I was found in the urine samples of the female workers. The highest and lowest concentrations of ${ }^{131} \mathrm{I}$ in female workers were $389.95 \pm 11 \mathrm{BqL}^{-1}$ and $8.02 \pm 1.080 \mathrm{~Bq} / \mathrm{L}$. On the other hand the radioactivity concentrations of both ${ }^{99 \mathrm{~m}} \mathrm{Tc}$ and ${ }^{131} \mathrm{I}$ were found in urine samples of the male workers. For male workers the highest detected radioactivity concentrations of ${ }^{99 \mathrm{~m}} \mathrm{Tc}$ and ${ }^{131} \mathrm{I}$ were $1529.5 \pm 36.05 \mathrm{BqL}^{-1}$ and $260.85 \pm 5.694 \mathrm{BqL}^{-1}$ respectively, whereas the lowest detected radioactivity concentrations were $24.47 \pm 2.14 \mathrm{BqL}^{-1}$ and $5.78 \pm 0.861 \mathrm{BqL}^{-1}$ respectively.

It was inferred that the worker with ${ }^{131}$ I concentration in urine might inhale ${ }^{131} \mathrm{I}$ radionuclide which was diffused into the air because of its volatile nature, during the distribution job of ${ }^{131} \mathrm{I}$. The possible reason for ${ }^{99 \mathrm{~m}} \mathrm{Tc}$ concentration in urine is for unconscious manipulation in the workplace. Even though the radiation contamination by occupational worker is low in Bangladesh, continued vigilance should be maintained to minimize this concentration as much as possible.

\section{Measurement of effective dose}

The effective dose of ${ }^{131} \mathrm{I}$ and ${ }^{99 \mathrm{~m}} \mathrm{Tc}$ in urine samples of occupational staff were calculated using equations (2) and (3). The 
result of committed effective dose of ${ }^{99 \mathrm{~m}} \mathrm{Tc}$ and ${ }^{131} \mathrm{I}$ in urine samples of occupational staff is also given in Table $1 \& 2$.

Due to manipulate the unsealed source of ${ }^{131} \mathrm{I}$, the highest and lowest effective doses were $7.67 \mu \mathrm{Sv}$ and $0.114 \mu \mathrm{Sv}$ respectively, for handling $2000 \mathrm{mCi}$ and $100 \mathrm{mCi}$ of ${ }^{131} \mathrm{I}$ radionuclide. On the other hand the highest and lowest effective doses $71.70 \mu \mathrm{Sv}$ and $1.15 \mu \mathrm{Sv}$ respectively, for handling $560 \mathrm{mCi}$ and $120 \mathrm{mCi}$ of ${ }^{99 \mathrm{~m}} \mathrm{Tc}$ radionuclide.
The effective doses of occupational workers due to inhalation and contamination of ${ }^{131} \mathrm{I}$ and ${ }^{99 \mathrm{~m}} \mathrm{Tc}$ radionuclides were found low in comparison with annual effective dose of an occupational worker which is $20 \mu \mathrm{Sv}$. The results of concentrations and doses can contribute to improve through regulations and deciding the radiological policies for the internal dosimetry of the radiation staff handling the radioisotopes in the medical fields.

Table I Measurement of activity concentration and effective doses of occupational workers for ${ }^{|3|}$

\begin{tabular}{|c|c|c|}
\hline No. of occupational worker & 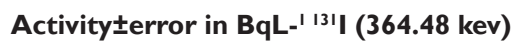 & Effective dose $(\mu \mathrm{S} v)$ for ${ }^{|3|} \mid$ \\
\hline I & $86.67 \pm 3.069$ & I.71 \\
\hline 2 & $58.86 \pm 2.476$ & 1.16 \\
\hline 3 & $155.22 \pm 5.350$ & 3.05 \\
\hline 4 & $5.78 \pm 0.861$ & 0.114 \\
\hline 5 & $9.79 \pm 1.654$ & 0.193 \\
\hline 6 & $8.02 \pm 1.080$ & 0.158 \\
\hline 7 & $161.8 \pm 6.264$ & 3.18 \\
\hline 8 & MDL & 0 \\
\hline 9 & MDL & 0 \\
\hline 10 & MDL & 0 \\
\hline II & $9.22 \pm 0.16$ & 0.181 \\
\hline 12 & MDL & 0 \\
\hline 13 & $33.15 \pm 2.40$ & 0.652 \\
\hline 14 & MDL & 0 \\
\hline 15 & MDL & 0 \\
\hline 16 & $346.4 I \pm 7.407$ & 6.82 \\
\hline 17 & $260.85 \pm 5.694$ & 5.13 \\
\hline 18 & $59.53 \pm 2.87$ & 1.17 \\
\hline 19 & $389.95 \pm 11$ & 7.67 \\
\hline 20 & $12.46 \pm 1.545$ & 0.245 \\
\hline
\end{tabular}

Table 2 Measurement of activity concentration and effective doses of occupational workers for ${ }^{99 \mathrm{~m} T c}$

\begin{tabular}{|c|c|c|}
\hline No. of occupational worker & Activity \pm error in $\mathrm{BqL}^{-1} 99 \mathrm{~m} \mathrm{Tc}(140.47 \mathrm{Kev})$ & Effective dose ( $\mu \mathrm{Sv})$ for ${ }^{99 \mathrm{~m} T \mathrm{~T}}$ \\
\hline 21 & $41.13 \pm 2.772$ & 1.93 \\
\hline 22 & $66.49 \pm 0.003$ & 3.12 \\
\hline 23 & $107.49 \pm 4.48$ & 5.04 \\
\hline 24 & $31.48 \pm 2.48$ & $\mathrm{I} .47$ \\
\hline 25 & MDL & 0 \\
\hline 26 & $1040.7 \pm 19.3$ & 48.8 \\
\hline 27 & MDL & 0 \\
\hline 28 & I I02.73 26.3 & 51.7 \\
\hline 29 & $670.25 \pm 21.4 \mathrm{I}$ & 31.4 \\
\hline 30 & $24.47 \pm 2.14$ & I.I5 \\
\hline 31 & $123.38 \pm 10.73$ & 5.78 \\
\hline
\end{tabular}


Table Continued..

\begin{tabular}{lll}
\hline No. of occupational worker & Activity \pm error in BqL & Effective dose $(\boldsymbol{\mu S v})$ for ${ }^{99 \mathrm{~m}} \mathbf{T c}(\mathbf{1 4 0 . 4 7 K e v})$ \\
\hline 32 & MDL & 0 \\
33 & $144.52 \pm 7.89$ & 6.77 \\
34 & $51.37 \pm 4.68$ & 2.41 \\
35 & $50.81 \pm 3.092$ & 2.38 \\
36 & $1529.5 \pm 36.05$ & 71.7 \\
37 & $243.83 \pm 12.19$ & 11.4 \\
\hline
\end{tabular}

\section{Conclusion}

The experimental results showed that the procedures on internal monitoring are very useful for controlling of radiation workers working with unsealed radioactive sources, in particular, in the

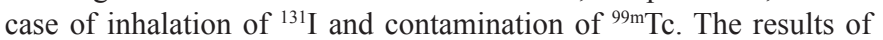
activity concentration due to intake of ${ }^{131} \mathrm{I}$ and ${ }^{99 \mathrm{~m}} \mathrm{Tc}$ can contribute to improve the regulations and deciding the radiological policies for internal dosimetry of radiation workers handling the radioisotopes in the nuclear medicine fields. The result also shows that the nuclear medicine occupational workers in Bangladesh are not in risk of radiation hazards. Even though the ${ }^{131} \mathrm{I}$ concentration in urine of nuclear medicine staff in Bangladesh is low, the occupational staff in nuclear medicine practices of Bangladesh should try to keep this concentration as low as possible. Proper working environment should be established such as suitable ventalation system, fume hood, musk, to avoid inhalation and contamination of ${ }^{131} \mathrm{I}$ and ${ }^{99 \mathrm{~m}} \mathrm{Tc}$ respectively. Finally, this study can be expanded to a basic one for guaranteeing the reliability for the results of internal doses for handling of ${ }^{131} \mathrm{I}$ and ${ }^{99 \mathrm{~m} T c \text {. }}$

\section{Acknowledgements}

None.

\section{Conflict of interest}

Author declares that there is no conflict of interest.

\section{References}

1. Dantas BM, Lucena EA, Dantas ALA. Internal exposure in nuclear medicine: Application of IAEA Criteria to Determine the Need for Internal Monitoring. Braz Arch Biol Technol. 2008;51:103-107.

2. Lucena EA, Rebelo AM, Araújo F, et al. Evaluation of Internal Exposure of Nuclear Medicine Worker through in vivo and in vitro Bioassay Techniques. Radiat Prot Dosimetry. 2007;127(1-4):465-468.

3. Ferdous MJ, Alam Z, Khan RK, et al. Internal Radiation monitoring of occupational staff in Nuclear medicine facility. Bangladesh Journal of Medical Physics. 2012;5(1):63-70.

4. International Commission on Radiological Protection. Age-dependent Doses to Members of the Public from Intake of Radionuclides-Part 4 Inhalation Dose Coefficients. UK: ICRP Publication, Pergamon Press; Ann ICRP. 1995;25(3-4).

5. International Commission on Radiological Protection. Individual monitoring for internal exposure of workers. UK: ICRP Publication 78, Pergamon Press. Ann ICRP. 1997;27(3-4). 